\title{
Restructuring physics labs to cultivate sense of student agency
}

\author{
Z. Yasemin Kalender $\odot,{ }^{1,2, *}$ Emily Stump $\odot,{ }^{2}$ Katelynn Hubenig $\odot,{ }^{3}$ and N. G. Holmes $\oplus^{2}$ \\ ${ }^{1}$ Derek Bok Center for Teaching and Learning, Harvard University, Cambridge, MA \\ ${ }^{2}$ Laboratory of Atomic and Solid State Physics, Department of Physics, \\ Cornell University, Ithaca, New York 14850, USA \\ ${ }^{3}$ Department of Physics and Astronomy, University of Calgary, Calgary, Alberta, Canada T2N1N4
}

(Received 6 May 2021; accepted 25 August 2021; published 1 October 2021)

\begin{abstract}
Instructional physics labs offer students unique opportunities to develop an understanding of experimentation. By transforming labs to be more open ended and experimentation focused, instructors can better support student agency and choice. In this study, we examine students' overall sense of and perceptions about agency in two experimentation-focused labs: one course primarily taken by physics majors and another course primarily taken by engineering majors. We compare the sense of and perceptions about agency between the different courses and between men and women in each course. Between the start and the end of the semester, we found a positive shift in students' sense of agency in the lab activities in both courses, with no difference between men's and women's shifts. Additionally, we found empirical evidence that the majority of the students preferred the final, most open-ended Project lab. Our qualitative analysis revealed that most of the students perceived the opportunities for agency positively, citing "freedom" as their reason for preferring the Project lab. Both women and men in the course for engineering majors showed similar patterns. Fewer women in the physics majors course, however, chose the final project lab as their favorite and less often attributed their preference to freedom. We discuss possible interpretations of these results and implications for instruction.
\end{abstract}

DOI: 10.1103/PhysRevPhysEducRes.17.020128

\section{INTRODUCTION}

In physics education, instructional laboratory classes (labs) offer valuable opportunities for engaging students in experimental physics. In labs, students can experience authentic science practice, such as gaining a more profound understanding of experimental methods and acquiring an ability to critically argue from evidence. However, many physics lab courses do not provide opportunities for such science practices because they are highly structured, procedural, and content reinforcing [1]. Engaging in scientific experimentation involves making many independent and substantial decisions, such as generating models, proposing testable hypotheses, designing experiments, interpreting experimental results, and maintaining skepticism throughout [2]. To make such decisions, students should be able to enact their agency: the capacity to guide one's actions towards achieving a goal $[3,4]$.

The purpose of this study is to investigate students' sense and perceptions of agency in an experimentation-focused lab. In particular, we sought to answer the following

\footnotetext{
*zykalender@fas.harvard.edu
}

Published by the American Physical Society under the terms of the Creative Commons Attribution 4.0 International license. Further distribution of this work must maintain attribution to the author(s) and the published article's title, journal citation, and DOI. research questions: (RQ1) To what degree do students recognize their agency in labs? (RQ2) What opinions do students form about more open-ended labs that intend to support student agency? (RQ3) How do these recognitions and opinions differ between different student groups (i.e., men or women and physics or engineering majors)?

\section{BACKGROUND}

\section{A. What does it mean to be "agentic"?}

Given the extensive discussion of agency in education research, we first articulate several forms of student "agency" that will be relevant for our study. Our agency framework draws from Bandura's work on social cognitive theory, where agency is described as the "individuals" capacity to exercise control... [and] to intentionally make things happen by one's action" [ [5], p. 2]. Bandura explains what it means to be agentic by contrasting agents to computers. Computers function as "input-output" systems and perform many cognitive operations to solve problems, yet they lack consciousness and the ability to make independent choices. In other words, computers can be considered more like "actors" performing the given tasks by following a script. On the other side of this spectrum, an autonomous entity can make choices without any constraints. An agent sits between these two extremes making independent decisions within constraints [6]. 
In conducting an experiment, physicists, as agents, face constraints in their projects. They need to consider limitations of their experiment, including but not limited to, generalizability of their results, risk mitigation, and budget allowance. Within these limits, however, they can make many independent choices and deliberate decisions when directing and carrying out their investigation. As highlighted in Bandura's discussion of agency, enacting agency requires "purposive accessing and deliberative processing of information for selecting, constructing, regulating, and evaluating courses of action" [5] (p. 3). Based on Bandura's characterization of agency, we can conceptualize agency in physics labs such that students acting with agency may investigate their own research inquiries, make deliberate choices in their experimental designs, or choose appropriate analysis methods and tools.

Agency is also used in other frameworks in science education [7-10]. For instance, critical science agency uses agency through a sociocultural lens and aims to understand the way students gain science literacy, develop characteristics of a critical thinker, and become more socially just individuals within the domains of science [11], math [12], engineering [13], and physics [14]. From this point of view, students would particularly value opportunities for agency that are relevant to the real world. The amount of open endedness in a lab, therefore, may not be perceived as supporting students' agency if not tied to real-world issues.

In summary, agency in this work relates to the degree of decision making by the agent given external constraints (that is, available choice and freedom or control to make choices) and the purposiveness of that decision making (such as to make positive change in the real world).

\section{B. How does agency relate to lab instruction?}

Traditionally, physics labs have been taught with little student choice in experiments [15]. Many of the experimental tasks in traditional labs are introduced to students as a to-do list (like chores) and students are supposed to complete the given activities in the worksheet with little room to independently direct their experiments [16]. As traditional labs mainly focus on teaching students how to use equipment and take measurements to verify wellknown physics theories, students miss a major opportunity to experience the nonlinear and complex nature of doing science.

The American Association of Physics Teachers' recommendations for the goals of instructional labs supports moving away from traditional teaching methods in favor of supporting more student agency [2]. Labs that support student agency better involve students in their learning processes so they can construct new knowledge through observation and self-reflection [17] and can better reflect an authentic research experience [18,19]. When given choice during lab instruction, students are more engaged [20] and develop confidence [21], ownership [22,23], more expertlike perceptions of experimentation [24,25], and increased engagement in expertlike experimentation behaviors $[6,25]$.

Despite the many benefits of more open-ended lab formats for students' outcomes, there can be some challenges creating student buy-in when implementing more open-ended instruction. For example, students' experiences in high school science courses vary widely [26]. Some students will have experienced traditionally taught physics labs in high school [27] while others may have never taken a physics lab course in their pre-college education (though others still may have experienced very innovative, openended labs). Many first-year students might be unaccustomed to or unfamiliar with an open-ended lab format and therefore may develop a resistance to this sudden shift. For instance, students worry about other student-centered learning methods because of a "fear of being in control" or because "more effort and thinking is required" [28]. Students may also feel less comfortable with the lack of structure and guidance [29] and prefer more authoritative instruction [30], despite learning more [31].

To accomplish a successful course implementation, instructors need to address these concerns as early as possible in the semester. Setting clear objectives for students, explaining the big picture learning goals, and giving explicit reasoning for the instructional format can be valuable for student buy-in [32]. Additionally, instructional models such as the cognitive apprenticeship model recommend beginning a course with higher levels of instructor guidance and support and slowly fading the support over time as students develop expertise. Additional support early on can alleviate some of the student worries about low instructor support. Furthermore, careful, deliberate, and timely feedback can support students in evaluating their own learning and reflecting critically on their experimentation decisions [33]. This instructor guidance, however, needs to vary throughout the instruction in a way that students can become more independent learners as they develop decision-making skills [34]. In other words, we can gradually reduce the structure in the lab by incrementally providing students more opportunities to make their own choices and decisions.

In this sense, the labs in this study begin with a more guided inquiry format and transition into more openinquiry as the semester progresses [35,36]. Our previous work has demonstrated the ways in which students' agency is better supported in these types of labs, leading to improvements in their attitudes towards and engagement in experimental physics practices [6,25]. In this study, we seek to evaluate students' perceptions of that agency, given a possible negative response, akin to that observed in active learning contexts. Our expectation is that the gradual shift in available agency supports students in transitioning their expectations about opportunities for agency in the course. 


\section{How do different student groups experience agency in labs}

Students across many science, technology, engineering, and mathematics (STEM) majors are required to take physics lab courses as a foundation to their academic training. Thus, these diverse learners can have different motivation and achievement goals in taking these courses. On the one hand, those who intend to major in physics can regard physics labs as relevant to and aligned with their academic aspirations, which can lead to a more intrinsic motivation (i.e., mastery goals) [37]. On the other hand, those who intend to major in engineering or other science majors can regard these courses as frustrating barriers to overcome or hoops to jump through in order to continue in their academic programs, which can lead to a more extrinsic motivation (i.e., performance goals) [37]. Depending on their learning motivation (extrinsic vs intrinsic), students' perceptions about and affinities towards a course may vary, which then can affect how they engage with the learning settings [38].

Students' motivation in a course may also depend on the particular learning goals or instructional strategies [39]. For instance, physics majors with more mastery-goal orientations might be motivated to develop an appreciation of the labs because they reflect the practices of experimental physics. Alternatively, physics majors who intend to pursue theoretical physics may be less motivated for the same reason. Engineering majors with performance goal orientations (such as because the course seems less relevant to their major) may negatively perceive the agency in the labs because they require more active student participation and engagement [28].

Additionally, women and men may also perceive agency in lab instruction differently. Bandura links agency to the individual's self-efficacy (the individual's beliefs about their own abilities): "efficacy beliefs are the foundation of human agency" [5] (pg. 10). Research has repeatedly found that women express lower self-efficacy than men [40-43], even when they have similar or higher academic performance $[44,45]$.

Based on the substantial research on self-efficacy differences across gender, we expect that these gaps in self-efficacy may translate into students' willingness to become more agentic learners. In a longitudinal study of chemical engineering majors, women were found to have lower confidence in their ability and take less active roles in cooperative group work than their male counterparts [46]. This study also found that men felt more benefits from group work where they had more active involvement by explaining things to others [46]. Research in physics has also found similar gendered interactions in lab environments, with women socialized into less active roles in experiments [47-49]. One study showed that students can associate lab roles as feminine or masculine depending on how passive or active the work is [47].
Particularly in more open-ended labs, these active and passive roles can relate to the degree to which the students are engaging in the decision-making discourse-that is, enacting their agency. For example, if one student takes charge in a group and dominates the discourse [50,51], other students might not perceive the agency afforded to them in the instruction. In general, men more often take charge of group work or dominate class discourse [52-55], suggesting women may experience agency in labs differently than men. In a study of science Ph.D. students' experiences, women more often report being ignored and interrupted by their male colleagues and feeling discomfort with the "combative style of communication" in their research group [56]. Mimicking authentic scientific practice, therefore, may actually diminish female students' agency in lab settings.

Based on these various student experiences in physics courses, and the demonstrated benefits of labs that support student agency, we examined students' perceptions towards the agency in lab: whether they sense and appreciate the available agency in the lab. In addressing RQ1, we first examined all students' sense of agency over time with a pre- and post-test survey. In RQ2, we investigated students' perceptions of the labs. Particularly, we examined their favorite lab unit and reasons why it was their favorite. Finally, in RQ3 we expand RQ1 and RQ2 by comparing student groups across course and gender.

\section{METHODS}

\section{A. Data collection, lab context, and participants}

The participants were students from intro-level mechanics courses at Cornell University. We collected data from two semesters of instruction from two physics courses: one course primarily taken by physics majors (majors) and one course primarily taken by engineering majors (engineering). Both of these courses focus on classical mechanics and kinematics at the introductory level and they use the same lab curricula $[57,58]$. Data in the majors course were collected during in-person instruction and data in the engineering course were collected in Spring 2020, when, by the sixth week of lab, the university transitioned to online instruction due to COVID-19. During this shift, the instructors modified the final lab unit in a way that supported remote instruction while still maintaining the agency of its design.

We analyzed responses from 66 students in the majors course and 246 students in the engineering course. In addition to the differences in students' majors across the two courses, the gender distribution was also distinct, with $50 \%$ women in the engineering course and less than $30 \%$ women in the majors course.

Labs were associated with the main lecture course and taught by graduate teaching assistants (TAs). Each lab session was two hours long and each lab unit typically 


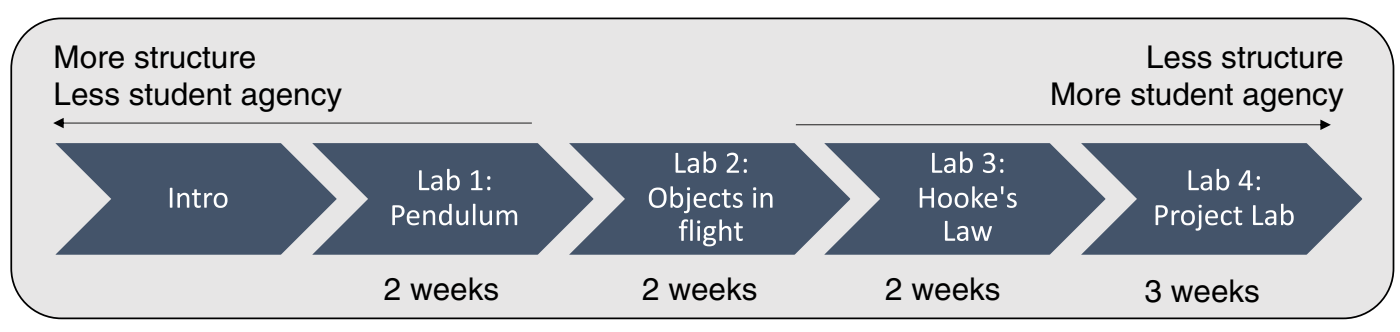

FIG. 1. The diagram shows the timeline of the lab units in the courses. Available student agency increases and structure decreases as students proceed from lab unit 1 to lab unit 4 (Project lab).

spanned two sessions. In a 15-week semester, there were 10 weeks of lab (Fig. 1). Students conducted their experiments in groups of two or three students (including during the period of emergency remote teaching for the Engineering course). Between each lab unit, students picked different lab partners. The first lab session (Intro) was an introductory unit, where students took the motivation survey and conceptual tests. In the rest of the lab session, students did small whiteboard activities in groups but they did not conduct any experiments. Afforded student agency in the remaining lab units (Lab 1, Lab 2, Lab 3) was gradually increased towards a final student-guided "project lab" (see Fig. 1). In the final project lab unit, students picked their own research question and designed the whole lab investigation, culminating in a group presentation during the third week of the unit. Students in the majors course took the post-test during the final session and after the presentations. Students in the engineering course took part of the post-test during the final session and after the presentations and the other part in their own time outside of class. In the majors course, students primarily designed their projects using the range of lab equipment made available to them in the rest of the course. In the engineering course, students designed their projects using materials found around the house (due to the shift to emergency remote teaching). Otherwise, the instructions for the labs were almost identical.

\section{B. Measuring sense of agency}

We developed a motivational survey measuring students' attitudes and beliefs towards physics experimentation. The survey included several latent variables, but here we focus on one particular construct: Sense of agency [59]. The sense of agency construct was composed of four items measuring students' beliefs about how much control they have in their experimental steps. All items were asked using a five-point Likert scale (from 1 to 5).

The initial validity and reliability of the sense of agency construct was reported in our previous study [59], which also includes partial analysis of the data from the majors course. Our prior analysis found that students' sense of agency increases within the semester for physics majors. Here we also evaluate the sense of agency of students in the engineering course, which is a broader and more diverse student population. We use $t$ tests and Cohen's $d$ to investigate whether average sense of agency scores showed significant shifts through the semester. Statistical $F$ tests demonstrated that the variance between pre- and post-test groups were indistinguishable $(p=0.234)$, so we could use paired $t$ tests assuming equal variances. We also conduct basic validity tests (Cronbach's alpha and confirmatory factor analysis) for the new dataset. Cronbach's alpha values were 0.87 and 0.86 for the majors and engineering courses, respectively, indicating a good internal reliability among items [60]. We also analyzed the entire survey through a factor analysis. The factor loading results for the four sense of agency items are given in Table I and show strong internal consistency (all items loading strongly to a single factor).

\section{Measuring perceptions of agency}

We also investigate students' perception of agency via open-ended questions, administered at the post-test. We asked: "What was your favorite lab unit this semester? You may select more than one choice." Students were also asked to explain their preference for the specific unit.

Students' responses were coded using a modified version of the reasoning scheme from our previous study [59]. Two researchers independently coded half of the data. We focus here on one code, "freedom," where students described their autonomy, freedom, or choice in the lab, particularly

TABLE I. Sense of agency items and their factor loading $(\lambda)$ values for both physics courses are shown below.

\begin{tabular}{lcc}
\hline \hline Items & Majors & Engineering \\
\hline $\begin{array}{l}\text { I am in control of setting the goals for the } \\
\text { experiments. }\end{array}$ & 0.859 & 0.819 \\
$\begin{array}{l}\text { I have the freedom to design and conduct } \\
\text { the best possible experiment to attain }\end{array}$ & 0.860 & 0.812 \\
$\quad \begin{array}{l}\text { my goals. } \\
\text { I am in control of choosing the } \\
\quad \begin{array}{l}\text { appropriate analysis tools to evaluate } \\
\text { experimental outcomes. }\end{array}\end{array}$ & 0.733 & 0.767 \\
$\begin{array}{l}\text { I am in control of doing interesting } \\
\text { experiments in a physics lab. }\end{array}$ & 0.723 & 0.712 \\
\hline \hline
\end{tabular}






FIG. 2. Raincloud plot [62] presents the shift in students' sense of agency scores from pre- to post-test by gender in two physics courses with the same lab curricula. The box plot indicates the median, interquartile range, and the full range of scores. The figure also includes the mean and standard errors, with dotted lines indicating the shift in the mean sense of agency by gender.

related to making decisions. Examples of responses coded as freedom include:

"I like how we had the freedom to design our own objective of each lab, come up with a procedure of our own, and analyze the results depending on a choice of our own."

"We were able to design our own experiments and investigate things we found interesting."

Rater agreement on the freedom code was $95 \%$ with a Cohen's kappa of 0.88 . Any disagreements were resolved through discussion between the two primary coders and, in some cases, a third coder. The full reasoning scheme with interrater reliability results are found in Table III.

To address the second part of RQ3, we matched students' self-reported gender with their survey responses and examined the proportion of students of each gender that were coded for freedom versus the other codes in their reasoning for their favorite lab.

\section{RESULTS}

\section{A. Students' sense of agency}

To address our first research question, we examined the students' pre- and post-test scores on the sense of agency construct (Fig. 2). Students in the majors course, on average, had neutral sense of agency pretest scores $(M=2.96, \quad \mathrm{SD}=0.98)$, indicating students neither expected low or high agency in college labs based on their previous physics lab experiences. At the end of the course, students' average sense of agency scores increased to $M=3.74$, $\mathrm{SD}=0.84$. This change from pretest to posttest $(95 \%$ confidence interval $[0.48,1.07])$ was statistically significant $[t(56)=5.29, p<0.001]$ with a medium to large effect size $(d=0.76)$ [61].

Students in the engineering course also started with neutral sense of agency scores $(M=3.05, \mathrm{SD}=0.84)$ and ended with positive sense of agency scores $(M=3.99$, $\mathrm{SD}=0.77)$, on average. The shift (95\% confidence interval $[0.81,1.07])$ was statistically significant $[t(245)=14.21$, $p<0.001]$, with a large effect size $(d=1.17)$ [61].

In both courses, men and women indicated statistically indistinguishable sense of agency scores at pre- and posttest ( $p>0.1$ in all cases). Thus, men and women experienced similar increases in their sense of agency from the beginning to the end of the course. Thus, to answer RQ1, students recognize the increasing opportunities for agency as the labs progressed and, to answer part of RQ3, this recognition did not differ between students from the two courses (engineering versus physics majors) or between men and women. 
TABLE II. Percentage of men and women who indicated preference for the project lab or other labs (lab units 1,2 , and 3 in the majors course and lab units 1 and 2 in the engineering course).

\begin{tabular}{lccc}
\hline \hline & & Women & Men \\
\hline Majors & Project lab & $29 \%$ & $58 \%$ \\
& Other labs & $71 \%$ & $42 \%$ \\
Engineering & Project lab & $60 \%$ & $52 \%$ \\
& Other labs & $40 \%$ & $48 \%$ \\
\hline \hline
\end{tabular}

\section{B. Students' perceptions of agency}

To answer our second research question, we analyzed student responses to an open-response survey question asking students to select their favorite lab unit and explain why they choose this unit. Although students were given the option to select multiple units as their favorite, the majority of students (> 98\%) picked just one. The majority of students in both courses (58\% in the majors course and $57 \%$ in the engineering course) selected the Project lab as their favorite lab unit (Table II).

The lab unit preferences between female and male students were distinctly different in the majors course $\left[\chi^{2}(1162)=5.91, p\right.$ value $\left.=0.015\right]$, but not in the engineering course. While $60 \%$ of the female students in the engineering course selected project lab as their favorite (comparable to men in either course), only $29 \%$ of women in the majors course chose project lab as their favorite unit (Table II). Men's preferences between the two courses were indistinguishable $\left[\chi^{2}(1,156)=0.25, p\right.$ value $\left.=0.61\right]$.

The coding analysis indicated that, in both courses, when students chose the project lab as their favorite lab unit, their explanations were overwhelmingly coded as freedom (approximately $75 \%$ of students who chose project lab; Fig. 3). This code included anything related to students' agency, autonomy, freedom, or choice in the lab activity. In all cases, the freedom was specifically tied to the aspects of the experimentation process.

Women in the majors course, however, expressed explanations coded as freedom at much lower rates than male students and women in the engineering course, though this was still the most prominent reasoning category for describing the project lab (Fig. 3). Compared to the other groups, female students in the majors course who preferred the other lab units were almost uniformly spread between the other reasoning categories, with slight majorities for the apparatus, epistemology, and other codes (see Fig. 4 in the for the full reasoning distributions). This uniform distribution of reasoning patterns indicates there was no single reason why women in the majors course preferred the other units.
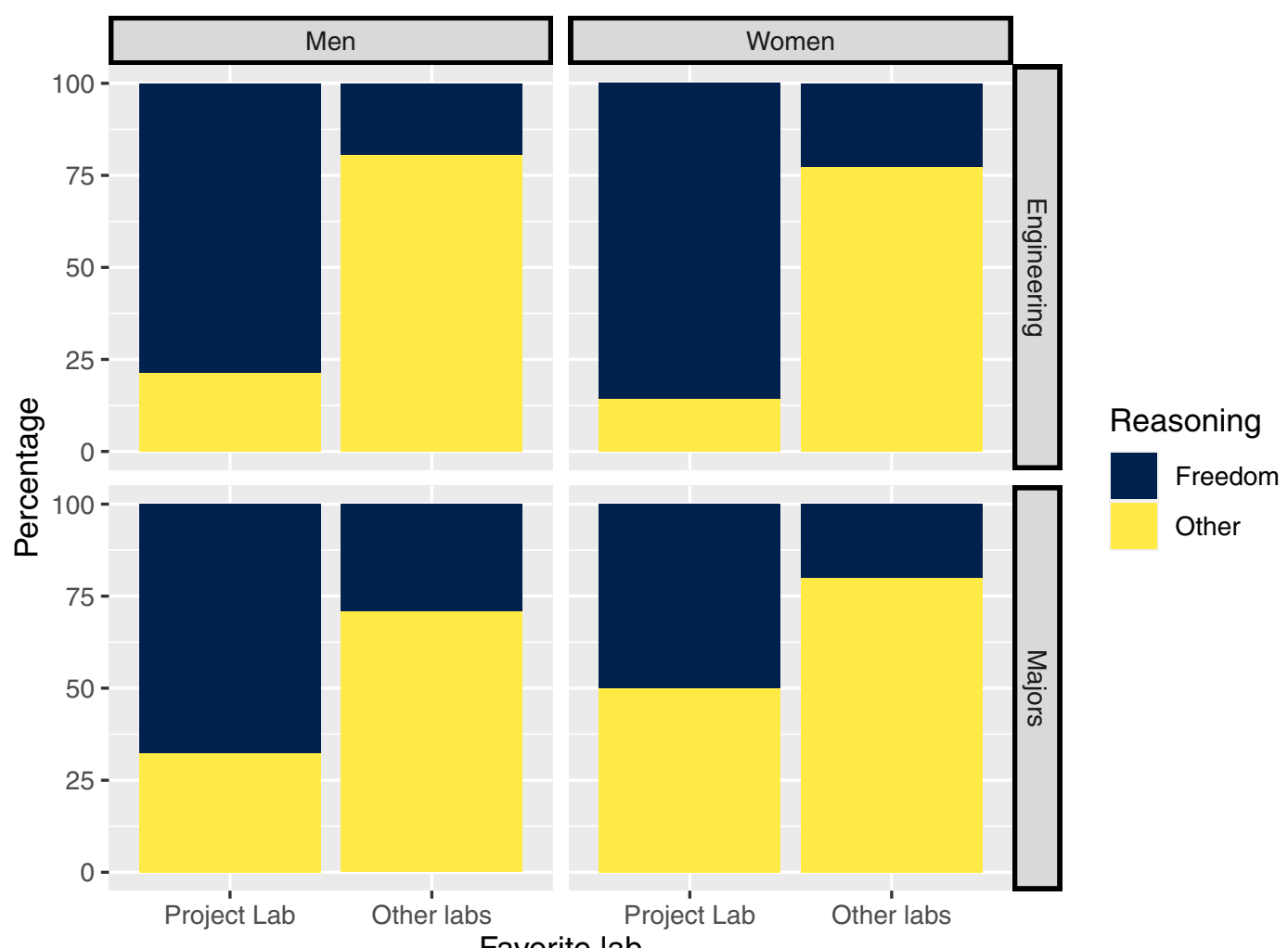

FIG. 3. Physics and engineering students' reasoning to their preferred lab unit as a percentage across gender, course, and favorite lab. For example, the first bar in the top left quadrant indicates, of the women in the engineering course who preferred project lab, the percentage of their explanations that were coded as freedom versus the other codes. 


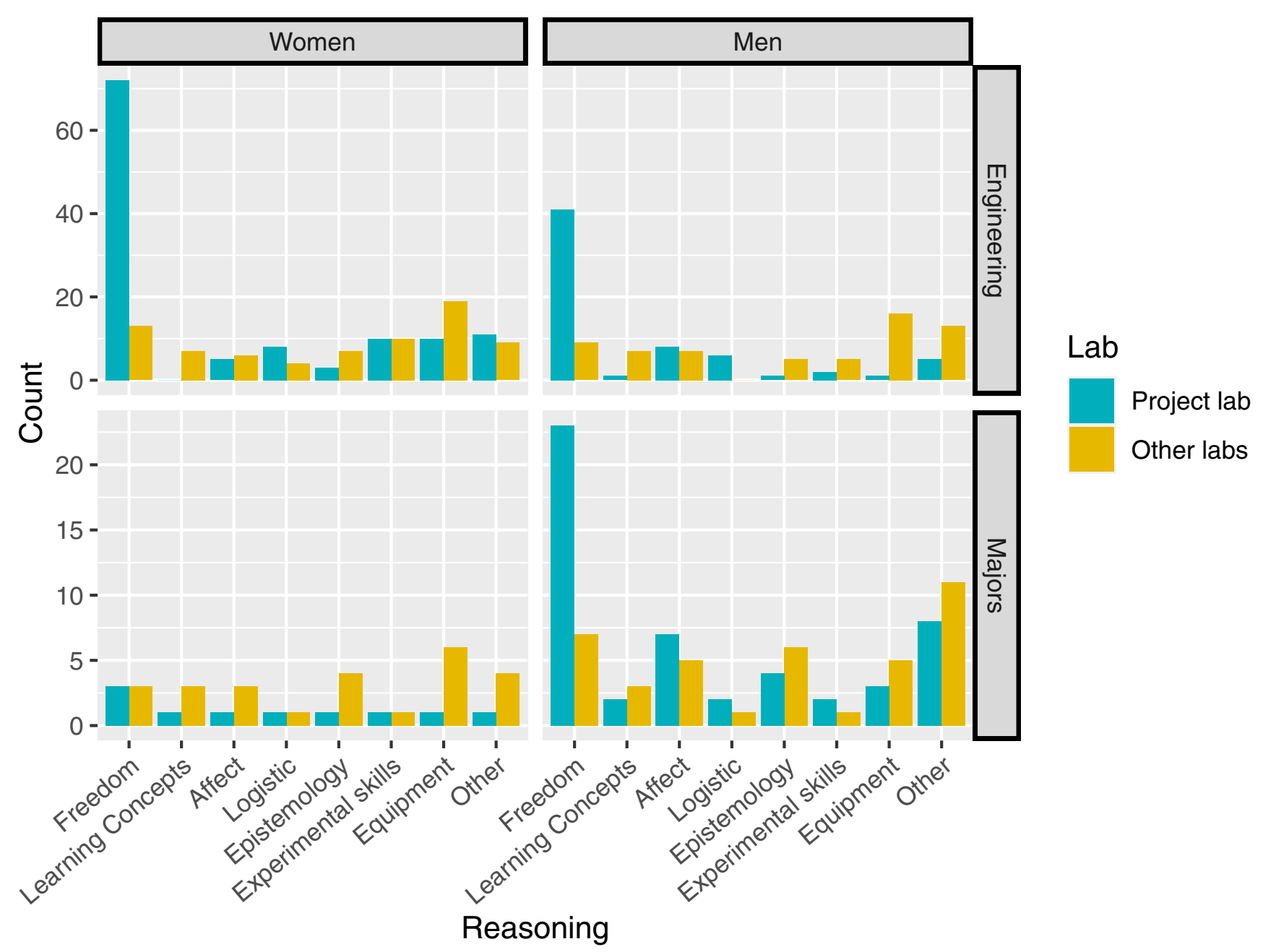

FIG. 4. Coding results of physics and engineering students' reasoning to their preferred lab unit. Students' responses could be coded under multiple reasoning categories.

\section{DISCUSSION}

In this paper, we examined students' sense of agency in and perceptions about experimentation-focused labs. To address RQ1, we evaluated how students' sense of agency in the lab changed from the beginning to the end of a semester of lab instruction. To address RQ2, we surveyed students about their reasoning for choosing a particular lab unit as their favorite and identified consistent themes in their responses. Finally in RQ3, we compared findings between men and women and between two physics courses with the same lab curriculum but different populations (primarily physics majors vs primarily engineering majors).

Students in both lab courses started with a neutral sense of agency scores, suggesting that students, on average, did not have a strong sense for how much control they should expect in the introductory physics labs. These findings may be unsurprising given that the majority of our students had just transitioned from high school to college and were taking their first college physics course. Most high school labs are taught using more traditional lab formats [63,64], and, even at the college level, open-ended physics lab instruction is still not as widespread as traditional formats. It is likely that students expect a more advanced lab format at college compared to their high school settings, but they might still not know the degree to which they have agency in their learning activities. The big challenge, therefore, is "communicating to students the expectations and goals of a particular laboratory design..., particularly when the designs are not traditional" [65]. To help manage students' expectations, instructors should clearly (and as early as possible) articulate the teaching methods in the course and how those methods will support the course's learning goals [66-70]. Our findings support that, by the end of the course, students recognized the goals and teaching methods of our reformed lab courses-namely, engaging students to make good decisions in their experimental practices-and found that agency to be positive.

Based on the cognitive apprenticeship model [34], our lab curriculum gradually decreased the amount of structure toward the end of semester, thus increasingly supporting 
student agency and choice. We expect students had an adjustment period as they were moved through the lab sequence and took up additional opportunities for agency. Against our expectations, students in both courses positively perceived this increased agency, as indicated by most students preferring the final, most open-ended project lab, particularly because of the "freedom" it afforded. This preference also existed despite constraints put on the project lab that limited the scope and scale of students' projects. This outcome contradicted one of our possible predictions that, based on research in critical science agency [11-14], students may not perceive or appreciate the agency afforded to them if it did not tie to real-world issues or opportunities to make change in the world.

The project lab unit can be considered the closest lab session to providing an authentic science experience by enabling students to experience freedom in what and how they investigate. With increased choice and opportunities for enacting agency, research suggests that students can become more engaged [20] and develop more confidence [3] and sense of ownership [22,23] in their investigations. Our findings further support the benefits of using guided inquiry on students' sense and perceptions of agency. The data, however, do not speak to how students might sense or perceive agency in a lab curriculum that starts with a high agency project lab or includes a single project that spans the whole semester. From the cognitive apprenticeship model [34] and research on student perceptions of student-centered lecture instruction [28-31,71], we expect students would likely be frustrated by or concerned about too much freedom at the outset. The intentional fading of structure to increasingly support agency may be necessary to scaffold students' experiences. For example, our recent study in an advanced chemical engineering course sequence suggested that students found that the first course in the sequence (which was relatively highly structured with limited choices) was necessary to prepare them for the unstructured nature of the second course (a 10-week fully open-ended project course) [72]. Future work should evaluate possible alternatives on the open-endedness of lab activities throughout an introductory lab course.

Additionally, reformed instructional methods can yield successful outcomes in one course but fail in another due to the broad spectrum of student values and goals in the course. During the first implementation of our labs (before this study took place), students in the majors and engineering courses responded and engaged with the new lab format differently. Course evaluations indicated that students in the engineering course experienced significant frustration with the labs, as compared to students in the majors course, particularly regarding not knowing what they were "supposed" to be doing. Over time, we modified and refined our reformed lab curricula by utilizing feedback from students and TAs in earlier semesters to better support students' expectations and more gently fade the scaffolding to support the transition to more open-ended labs. In this study, we observed that students in both courses, using the same lab curriculum, not only showed a similar increase in their sense of agency, but also viewed the agency as a positive feature of their favorite lab unit.

However, there were differences in the ways female students experienced the two courses. In the engineering course, we observed very similar statements from both men and women in terms of their favorite lab choices and reasonings. In the majors course, we found that very few female students selected the project lab as their favorite unit and mentioned freedom at lower rates. There may be several reasons for this disparity in men's and women's perceptions of agency only in the physics majors course. Women in the majors course were a numerical minority $(30 \%)$, whereas women were equally represented in the engineering course (50\%). This imbalanced demographic distribution can translate into imbalanced gender compositions in lab groups and lead to differential experiences [52]. Even though women are found to benefit more from cooperative group work [73], women have been found to take on more passive roles in physics labs [47-49,74] and participate less in discussion [52-55], which may impact their perceptions of agency. Much of the work has found these disparities in courses for nonphysics majors, however, leaving an important question as to why women in the majors course, but not the engineering course, demonstrated these differing perceptions.

One possibility is due to a key difference in the implementations of the two courses. Whereas the majors course took place during a fully in-person semester, the post-test from the engineering course was conducted after the shift to remote instruction in Spring 2020. Thus, the ways women perceive agency in in-person versus remote labs may be the key difference, not their majors. It is unclear, however, why the shift to remote instruction would affect the perceptions of women, but not men. Alternatively, because the number of women in the majors course was quite small, individual women's negative experiences in the project lab could have significantly affected the aggregate data. Future research should evaluate women's experiences in the more openended project lab at a finer granularity and examine potential interventions to better support women's perceptions of agency in the lab. We also plan to collect additional data from this population in subsequent semesters to evaluate whether the results here are indicative of a common trend or an isolated event.

Transforming a lab course to an open-ended format is a nontrivial task in many ways. For one, open-ended labs are relatively rare in physics education and more work is needed to refine and improve them. Lab instructor training to implement the reformed pedagogy is also essential, particularly when both the pedagogy and the content associated with the learning goals may be novel for many graduate students. Furthermore, many students are accustomed to traditional labs and it can be challenging to promote student buy-in regarding the open-ended and high student agency lab format. 
Even considering these challenges, our study further demonstrates that open-ended lab instruction is a great way to promote student engagement and enjoyment. Students can develop multiple scientific skills [25,75], develop more ownership in their experiments [22,23], and become more fully engaged [20]. Our results in this study demonstrate that these benefits do not come at a cost to students' perceptions and attitudes: they generally appreciate the agency afforded to them. However, the results also indicate that we need to better understand how best to implement these tools in our classes to support all students' experiences and perceptions.

\section{ACKNOWLEDGMENTS}

This material is based upon work supported by the National Science Foundation under Grant No. 1836617.
This work was partially supported by the Cornell University Active Learning Initiative project. We also thank Martin Stein for his early contributions to survey development. This study was conducted under IRB protocol No. 1802007733.

\section{APPENDIX}

Table III shows the full codebook for students' explanations to the question "What was your favorite lab unit this semester? You may select more than one choice." The codebook was adapted from our previous study [59], where categories were emergently and iteratively identified based on common themes. For this work, one category related to Remote Learning was added for the responses in the Engineering course because the last lab unit took place during the shift to emergency response teaching in Spring

TABLE III. The codebook for students' reasoning for their favorite lab unit with code names and their definition. Percent agreement and Cohen's kappa values are also given as an interreliability measure between the coders.

\begin{tabular}{|c|c|c|c|}
\hline Code name & Definition and examples & $\begin{array}{c}\text { Rater } \\
\text { agreement }\end{array}$ & $\begin{array}{c}\text { Cohen's } \\
\text { kappa }\end{array}$ \\
\hline Freedom & $\begin{array}{l}\text { Students describe autonomy in the lab, particularly related to making decisions. } \\
\text { "I like how we had the freedom to design our own objective of each lab, come up with a } \\
\text { procedure of our own, and analyze the results depending on a choice of our own." } \\
\text { "We were able to design our own experiments and investigate things we found } \\
\text { interesting." }\end{array}$ & $94.8 \%$ & 0.88 \\
\hline $\begin{array}{l}\text { Learning } \\
\text { concepts }\end{array}$ & $\begin{array}{l}\text { Students associate labs with reinforcing theory or helping them to understand theory, } \\
\text { lectures, or general course material. } \\
\text { "It was good to see the small angle approximation in action." } \\
\text { "It was very clear to see the effects of air drag on the graphs, especially when many } \\
\text { objects were used." }\end{array}$ & $94.8 \%$ & 0.69 \\
\hline Affect & $\begin{array}{l}\text { Students describe feelings or emotions that are directly related to the lab unit or group } \\
\text { mates. "It was easy and actually fun to do." } \\
\text { "It was fun to try to model objects in flight and make modifications like spinning vs. } \\
\text { throwing them straight" }\end{array}$ & $93.5 \%$ & 0.79 \\
\hline Logistics & $\begin{array}{l}\text { Students mention lab notes, duration of the lab, or how lab is organized, structured, or } \\
\text { scaffolded. "Least work outside class hours." } \\
\text { "My partners worked well and we did the lab quickly and efficiently and were able to } \\
\text { discuss." }\end{array}$ & $96.1 \%$ & 0.71 \\
\hline Epistemology & $\begin{array}{l}\text { Students express learning something new or how knowledge in the experiment is } \\
\text { acquired. } \\
\text { "I got to see how much drag can impact and realized why we consider it negligible." } \\
\text { "It was interesting to learn new things about experiments I did in high school. } \\
\text { It was surprising to see that I didn't quite know everything about it that } \\
\text { I once thought I did." }\end{array}$ & $96.1 \%$ & 0.82 \\
\hline $\begin{array}{l}\text { Experimental } \\
\text { skills }\end{array}$ & $\begin{array}{l}\text { Students mention learning lab-related skills such as using certain statistical tools, } \\
\text { collaborating with each other and/or being cognizant of biases in experiment. } \\
\text { "It helped me understand how to calculate if two measurements are distinguishable } \\
\text { from each other." } \\
\text { "I enjoyed using graphs to model and interpret data from the sensors." }\end{array}$ & $97.4 \%$ & 0.86 \\
\hline Equipment & $\begin{array}{l}\text { Students mention the objects, tools and/or apparatus used the lab session. } \\
\text { "We got to use force sensors." } \\
\text { "Using LoggerPro was really fun to see the actual graphs of what was happening." }\end{array}$ & $100 \%$ & 1 \\
\hline Other & Any other topics that were rare and not in the above categories. & $92.2 \%$ & 0.62 \\
\hline
\end{tabular}




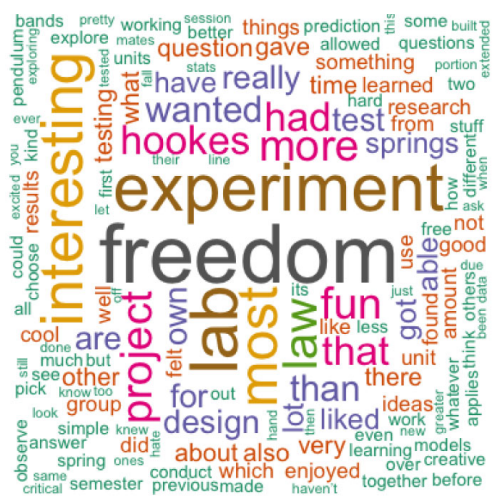

(a) Majors

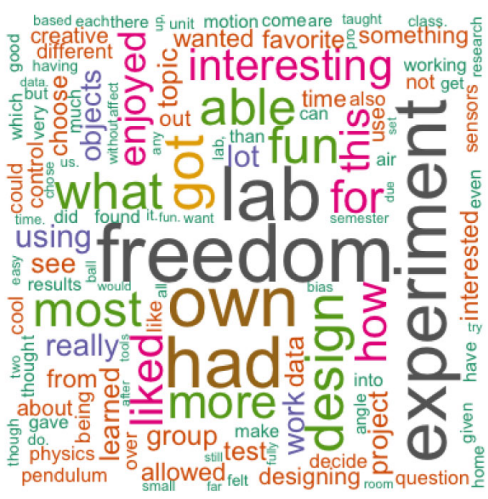

(b) Engineers

FIG. 5. Wordclouds show the most frequently used word for students' open-ended responses to why they liked a particular lab unit in the majors (left) and engineering (right) course. Freedom is the most frequently written word.

2020. The frequency of remote learning statements ended up being quite low, however, so we included such statements under the other reasoning category.

Two researchers independently coded half of the data. The modified reasoning scheme and kappa values (interrater reliability) are shown in Table III. While most of the kappa values indicated either strong or almost perfect agreement, two of the categories showed moderate levels of agreement between the coders $(>0.60$ and $<0.70)$ [76]. The disagreements were resolved by either two coders discussing them or a third coder (one of the researchers) resolving the disagreement.

The full counts of student responses across gender and course are shown in Fig. 4. We kept the results here as raw counts, rather than percentages, for simplicity. There were 66 students in the majors course (and fewer than $30 \%$ women) and 246 students in the engineering course (50\% women). Students' explanations could also be coded with more than one code, so the total count in each quadrant of the figure add to more than the number of students.

We also built wordclouds of students' reasoning for their favorite lab using the rquery.wordcloud() function in $R$. The wordcloud scales each word by the number of students that mentioned it. The wordclouds for the majors and engineering courses (Fig. 5) both indicate that freedom was a prominent theme in students' responses.
[1] S. Olson and D. G. Riordan, Engage to Excel: Producing One Million Additional College Graduates with Degrees in Science, Technology, Engineering, and Mathematics (Office of the President, Washington, DC, 2012).

[2] American Association of Physics Teachers, AAPT Recommendations for the Undergraduate Physics Laboratory Curriculum, Tech. Rep. (American Association of Physics Teachers, 2014).

[3] A. Bandura, Human agency in social cognitive theory, Am. Psychol. 44, 1175 (1989).

[4] A. Bandura, Reflections on human agency, Contemporary psychology in Europe: Theory, research and applications, edited by J. Georgas and M. Manthouli (Hogrefe \& Huber, Seattle, WA, 1996), pp. 194-210.

[5] A. Bandura, Social cognitive theory: An agentic perspective, Ann. Rev. Psychol. 52, 1 (2001).

[6] N. G. Holmes, B. Keep, and C. E. Wieman, Developing scientific decision making by structuring and supporting student agency, Phys. Rev. Phys. Educ. Res. 16, 010109 (2020).

[7] J. Arnold and D. John Clarke, What is "agency"? perspectives in science education research, Int. J. Sci. Educ. 36, 735 (2014).

[8] P. Bourdieu, Cultural reproduction and social reproduction, in Power and Ideology in Education, edited by J. Karabel and A. H. Hasley (Oxford University Press, New York, 2019), pp. 487-511.

[9] D. C. Holland, W. Lachicotte, D. Skinner, and C. Cain, Identity and Agency in Cultural Worlds (Harvard University Press, Cambridge, MA, 1998).

[10] A. C. Barton and E. Tan, We be burnin'! agency, identity, and science learning, J. Learn. Sci. 19, 187 (2010).

[11] S. J. Basu, A. B. Barton, N. Clairmont, and D. Locke, Developing a framework for critical science agency through case study in a conceptual physics context, Cult. Stud. Sci. Educ. 4, 345 (2009). 
[12] E. E. Turner, Critical mathematical agency: Urban middle school students engage in significant mathematics to understand, critique, and act upon their world, Ph.D. thesis, University of Texas, Austin, TX, 2003, an optional note.

[13] A. Godwin, G. Potvin, Z. Hazari, and R. Lock, Identity, critical agency, and engineering: An affective model for predicting engineering as a career choice, J. Eng. Educ. 105, 312 (2016).

[14] S. J. Basu and A. B. Barton, Critical physics agency: Further unraveling the intersections of subject matter knowledge, learning, and taking action, Cult. Stud. Sci. Educ. 4, 387 (2009).

[15] R. Trumper, The physics laboratory-A historical overview and future perspectives, Sci. Educ. 12, 645 (2003).

[16] C. Wieman, Comparative cognitive task analyses of experimental, science and instructional laboratory courses, Phys. Teach. 53, 349 (2015).

[17] E. von Glasersfeld, Learning as constructive activity, in Proceedings of the 5th Annual 083 Meeting of the North American Group of Psychology in Mathematics Education (PME-NA, Montreal, 1983), pp. 41-101.

[18] L. A. Corwin, C. R. Runyon, E. Ghanem, M. Sandy, G. Clark, G. C. Palmer, S. Reichler, S. E. Rodenbusch, and E. L. Dolan, Effects of discovery, iteration, and collaboration in laboratory courses on undergraduates' research career intentions fully mediated by student ownership, CBE Life Sci. Educ. 17, es1 (2018).

[19] C. A. Wei and T. Woodin, Undergraduate research experiences in biology: Alternatives to the apprenticeship model, CBE Life Sci. Educ. 10, 123 (2011).

[20] J. A. Schmidt, J. M. Rosenberg, and P. N. Beymer, A person-in-context approach to student engagement in science: Examining learning activities and choice, J. Res. Sci. Teach. 55, 19 (2018).

[21] E. Jeffery, K. Nomme, T. Deane, C. Pollock, and G. Birol, Investigating the role of an inquiry-based biology lab course on student attitudes and views toward science, CBE Life Sci. Educ. 15, 1 (2017).

[22] D. I. Hanauer, J. Frederick, B. Fotinakes, and S. A. Strobel, Linguistic analysis of project ownership for undergraduate research experiences, CBE Life Sci. Educ. 11, 378 (2012).

[23] D. R. Dounas-Frazer, J. T. Stanley, and H. J. Lewandowski, Student ownership of projects in an upper-division optics laboratory course: A multiple case study of successful experiences, Phys. Rev. Phys. Educ. Res. 13, 020136 (2017).

[24] B. R. Wilcox and H. J. Lewandowski, Open-ended versus guided laboratory activities: Impact on students' beliefs about experimental physics, Phys. Rev. Phys. Educ. Res. 12, 020132 (2016).

[25] E. M. Smith, M. M. Stein, C. Walsh, and N. G. Holmes, Direct Measurement of the Impact of Teaching Experimentation in Physics Labs, Phys. Rev. X 10, 011029 (2020).

[26] Office of Innovation U.S. Department of Education and Improvement, Stem 2026: A vision for innovation in stem education (2016).
[27] National Research Council, America's Lab Report: Investigations in High School Science, edited by S. R. Singer, Margaret L. Hilton, and Heidi A. Schweingruber (The National Academies Press, Washington, DC, 2006).

[28] K. M. Deters, Student opinions regarding inquiry-based labs, J. Chem. Educ. 82, 1178 (2005).

[29] K. Henige, Undergraduate student attitudes and perceptions toward low- and high-level inquiry exercise physiology teaching laboratory experiences, Adv. Physiol. Educ. 35, 197 (2011).

[30] D. C. Owens, T. D. Sadler, A. T. Barlow, and C. SmithWalters, Student motivation from and resistance to active learning rooted in essential science practices, Res. Sci. Educ. 50, 253 (2020).

[31] L. Deslauriers, L. S. McCarty, K. Miller, K. Callaghan, and G. Kestin, Measuring actual learning versus feeling of learning in response to being actively engaged in the classroom, Proc. Natl. Acad. Sci. U.S.A. 116, 19251 (2019).

[32] R. M. Felder, Hang in there! Dealing with student resistance to learner-centered teaching, Chem. Eng. Educ. 45, 131 (2011), https://www.engr.ncsu.edu/stem-resources/ legacy-site/.

[33] N. G. Holmes, C. E. Wieman, and D. A. Bonn, Teaching critical thinking, Proc. Natl. Acad. Sci. U.S.A. 112, 11199 (2015).

[34] A. Collins, J. S. Brown, and S. E. Newman, Cognitive Apprenticeship: Teaching the Craft of Reading, Writing and Mathematics (Technical Report No. 403) (Centre for the Study of Reading, University of Illinois, Cambridge, MA, 1987).

[35] M. R. Blanchard, S. A. Southerland, J. W. Osborne, V. D. Sampson, L. A. Annetta, and E. M. Granger, Is inquiry possible in light of accountability?: A quantitative comparison of the relative effectiveness of guided inquiry and verification laboratory instruction, Sci. Educ. 94, 577 (2010).

[36] L. B. Buck, M. H. Towns, and S. Lowery Bretz, Research and teaching: Characterizing the level of inquiry in the undergraduate laboratory, J. Coll. Sci. Teach. 38, 52 (2008), https://www.chem.purdue.edu/towns/Towns\% 20Publications/Bruck\%20Bretz\%20Towns\%202008.pdf.

[37] A. J. Elliot and H. A. McGregor, A $2 \times 2$ achievement goal framework, J. Personality Social Psychol. 80, 501 (2001).

[38] L. Nadelson, K. K. Hardy, and D. Yang, I like therefore I learn! Engineering student motivation to learn in their least and most favorite courses, in Proceedings of the 2015 ASEE Annual Conference \& Exposition (ASEE Conferences, Seattle, Washington, 2015).

[39] C.S. Dweck, Motivational processes affecting learning, Am. Psychol. 41, 1040 (1986).

[40] P. M. Huang and S. Gage Brainard, Identifying determinants of academic self-confidence among science, math, engineering, and technology students, J. Women Minorities Sci. Engin. 7, 315 (2001), https://eric.ed.gov/? $\mathrm{id}=$ EJ647921.

[41] P. Vincent-Ruz and C. D. Schunn, The increasingly important role of science competency beliefs for science learning in girls, J. Res. Sci. Teach. 54, 790 (2017). 
[42] M. Besterfield-Sacre, M. Moreno, L. J. Shuman, and C. J. Atman, Gender and ethnicity differences in freshmen engineering student attitudes: A cross-institutional study*, J. Engin. Educ. 90, 477 (2001).

[43] M. Beth Rosson, J. M. Carroll, and H. Sinha, Orientation of undergraduates toward careers in the computer and information sciences: Gender, self-efficacy and social support, ACM Trans. Comput. Educ. 11, 1 (2011).

[44] Z. Yasemin Kalender, E. Marshman, C. Schunn, T. J. Nokes-Malach, and C. Singh, Large gender differences in physics self-efficacy at equal performance levels: A warning sign?, in Proceedings of the Physics Education Research Conference 2018, Washington, DC (AIP, New York, 2018), https://doi.org/10.1119/perc.2018.pr Kalender.

[45] K. M. Whitcomb, Z. Yasemin Kalender, T. J. Nokes-Malach, C. Schunn, and C. Singh, Inconsistent gender differences in self-efficacy and performance for engineering majors in physics and other disciplines: A cause for alarm?, in Proceedings of the 2019 Physics Education Research Conference 2019, Provo, UT (AIP, New York, 2019), pp. 639-644, https://doi.org/10.1119/perc.2019.pr .Whitcomb.

[46] R. M. Felder, G. N. Felder, M. Mauney, C. E. Hamrin Jr., and E. Jacquelin Dietz, A longitudinal study of engineering student performance and retention. iii. gender differences in student performance and attitudes, J. Eng. Educ. 84, 151 (1995).

[47] A. T. Danielsson, Exploring woman university physics students 'doing gender' and 'doing physics', Gender Educ. 24, 25 (2012).

[48] D. Doucette, R. Clark, and C. Singh, Hermione and the secretary: How gendered task division in introductory physics labs can disrupt equitable learning, Eur. J. Phys. 41, 035702 (2020).

[49] K. N. Quinn, M. M. Kelley, K. L. McGill, E. M. Smith, Z. Whipps, and N. G. Holmes, Group roles in unstructured labs show inequitable gender divide, Phys. Rev. Phys. Educ. Res. 16, 010129 (2020).

[50] B. A. Archibeque, M. B. Kustusch, F. Genz, S. Franklin, and E. C. Sayre, Quantitative measures of equity in small group, in Proceedings of the 2017 Physics Education Research Conference, Cincinnati, $\mathrm{OH}$, edited by A. Traxler, Y. Cao, and L. Ding (AIP, New York, 2017).

[51] B. Archibeque, F. Genz, M. Franklin, S. Franklin, and E. Sayre, in Proceedings, Physics Education Research Conference 2017, Cincinnati, OH, (2017), WWW Document, https:/www.compadre.org/Repository/document/ ServeFile.cfm?ID=14566\&DoclD=4743.

[52] P. Heller and M. Hollabaugh, Teaching problem solving through cooperative grouping. part 2: Designing problems and structuring groups, Am. J. Phys. 60, 637 (1992).

[53] S. M. Aguillon, G.-F. Siegmund, R. H. Petipas, A. Grace Drake, S. Cotner, and C. J. Ballen, Gender differences in student participation in an active-learning classroom, CBE Life Sci. Educ. 19, ar12 (2020).

[54] E. J. Dallimore, J. H. Hertenstein, and M. B. Platt, Leveling the playing field: How cold-calling affects class discussion gender equity, J. Educ. Learn. 8, 14 (2019).

[55] N. A. Lewis, D. Sekaquaptewa, and L. A. Meadows, Modeling gender counterstereotypic group behavior: a brief video intervention reduces participation gender gaps on STEM teams, Social Psychol. Educ. 22, 557 (2019).

[56] S. E. Widnall, AAAS presidential lecture: Voices from the pipeline, Science 241, 1740 (1988).

[57] N. G. Holmes, Thinking Critically in Physics Labs (2020), https://www.physport.org/curricula/thinkingcritically/ index.cfm?

[58] N. G. Holmes and E. M. SmithOperationalizing the AAPT learning goals for the lab, Phys. Teach. 57, 296 (2019).

[59] Z. Y. Kalender, M. M. Stein, and N. G. Holmes, Sense of agency, gender, and students' perception in open-ended physics labs, in Proceedings of the 2020 Physics Education Research Conference, virtual conference (AIP, New York, 2020), pp. 259-265, https://doi.org/10.1119/perc.2020.pr .Kalender.

[60] L. J. Cronbach, Coefficient alpha and the internal structure of tests, Psychometrika 16, 297 (1951).

[61] J. Cohen, Statistical Power Analysis for the Behavioral Sciences (L. Erlbaum Associates, Hillsdale, NJ, 1998).

[62] M. Allen, D. Poggiali, K. Whitaker, T. R. Marshall, and R. A. Kievit, Raincloud plots: a multi-platform tool for robust data visualization, Wellcome Open Res. 4, 63 (2018).

[63] National Research Council, America's lab report: Investigations in high school science (National Academies Press, Washington, DC, 2006).

[64] A. Szott, Open-ended laboratory investigations in a high school physics course: The difficulties and rewards of implementing inquiry-based learning in a physics lab, Phys. Teach. 52, 17 (2014).

[65] R. L. Kung and C. Linder, Metacognitive activity in the physics student laboratory: is increased metacognition necessarily better?, Metacognition Learn. 2, 41 (2007).

[66] E. F. Redish, A theoretical framework for physics education research: Modeling student thinking, in Proceedings of the International School of Physics, Research on Physics Education, Vol. 156, edited by E. F. Redish and M. Vicentini (IOS Press, Varenna, Italy, 2003), pp. 1-64.

[67] J. D. H. Gaffney, A. L. Housley Gaffney, and R. J. Beichner, Do they see it coming? Using expectancy violation to gauge the success of pedagogical reforms, Phys. Rev. ST Phys. Educ. Res. 6, 010102 (2010).

[68] J. D. H. Gaffney and J. T. Whitaker, Making the most of your first day of class, Phys. Teach. 53, 137 (2015).

[69] C. L. Meaders, E. S. Toth, A. Kelly Lane, J. Kenny Shuman, B. A. Couch, M. Stains, M. R. Stetzer, E. Vinson, and M. K. Smith, "What Will I Experience in My College STEM Courses?" An Investigation of Student Predictions about Instructional Practices in Introductory Courses, CBE Life Sci. Educ. 18, ar60 (2019).

[70] A. Kelly Lane, C. L. Meaders, J. Kenny Shuman, M. R. Stetzer, E. L. Vinson, B. A. Couch, M. K. Smith, and M. Stains, Making a first impression: Exploring what instructors do and say on the first day of introductory STEM courses, CBE Life Sci. Educ. 20, ar7 (2021).

[71] C. L. Meaders, A. Kelly Lane, A. I. Morozov, J. Kenny Shuman, E. S. Toth, M. Stains, M. R. Stetzer, E. Vinson, B. A. Couch, and M. K. Smith, Undergraduate student concerns in introductory stem courses: What they are, how 
they change, and what influences them, J. STEM Educ. Res. 3, 195 (2020).

[72] E. Burkholder, L. Hwang, E. Sattely, and N. Holmes, Supporting decision-making in upper-level chemical engineering laboratories, Educ. Chem. Engin. 35, 69 (2021).

[73] L. Cen, D. Ruta, L. Powell, and J. Ng, Does gender matter for collaborative learning?, in Proceedings of the 2014 IEEE International Conference on Teaching, Assessment and Learning for Engineering (TALE) (IEEE, Bellingham, WA, 2014), pp. 433-440.
[74] J. Day, J. B. Stang, N. G. Holmes, D. Kumar, and D. A. Bonn, Gender gaps and gendered action in a first-year physics laboratory, Phys. Rev. Phys. Educ. Res. 12, 020104 (2016).

[75] E. Etkina, A. Karelina, M. Ruibal-Villasenor, D. Rosengrant, R. Jordan, and C. E. Hmelo-Silver, Design and Reflection Help Students Develop Scientific Abilities: Learning in Introductory Physics Laboratories, J. Learn. Sci. 19, 54 (2010).

[76] M. L. McHugh, Interrater reliability: The kappa statistic, Biochemia Medica 22, 276 (2012). 